\title{
Uncertainty of climate change impact on groundwater reserves - Application to a chalk aquifer
}

\author{
Pascal Goderniaux $^{\mathrm{a}, *}$, Serge Brouyère ${ }^{\mathrm{b}}$, Samuel Wildemeersch ${ }^{\mathrm{d}}$, René Therrien ${ }^{\mathrm{c}}$, Alain Dassargues ${ }^{\mathrm{b}}$ \\ ${ }^{a}$ Geology and Applied Geology, University of Mons, Rue de Houdain, 9, 7000 Mons, Belgium \\ ${ }^{\mathrm{b}}$ Hydrogeology and Environmental Geology - Aquapôle, Department ArGEnCo, Applied Sciences, University of Liège, Building B52/3, 4000 Liège, Belgium \\ ' Department of Geology and Geological Engineering, Université Laval, G1V 0A6 Quebec, Quebec, Canada \\ ' $S P A Q u E$ sa, Boulevard d'Avroy, 38/1, 4000 Liège, Belgium
}

\section{A R T I C L E I N F O}

\section{Article history:}

Received 9 March 2015

Received in revised form 5 June 2015

Accepted 8 June 2015

Available online 17 June 2015

This manuscript was handled by Peter K.

Kitanidis, Editor-in-Chief, with the

assistance of Christophe Darnault, Associate

Editor

\section{Keywords:}

Groundwater

Climate change

Uncertainty

Integrated model

HydroGeoSphere

UCODE

\begin{abstract}
S U M M A R Y
Recent studies have evaluated the impact of climate change on groundwater resources for different geographical and climatic contexts. However, most studies have either not estimated the uncertainty around projected impacts or have limited the analysis to the uncertainty related to climate models. In this study, the uncertainties around impact projections from several sources (climate models, natural variability of the weather, hydrological model calibration) are calculated and compared for the Geer catchment $\left(465 \mathrm{~km}^{2}\right)$ in Belgium. We use a surface-subsurface integrated model implemented using the finite element code HydroGeoSphere, coupled with climate change scenarios (2010-2085) and the UCODE_2005 inverse model, to assess the uncertainty related to the calibration of the hydrological model. This integrated model provides a more realistic representation of the water exchanges between surface and subsurface domains and constrains more the calibration with the use of both surface and subsurface observed data. Sensitivity and uncertainty analyses were performed on predictions. The linear uncertainty analysis is approximate for this nonlinear system, but it provides some measure of uncertainty for computationally demanding models. Results show that, for the Geer catchment, the most important uncertainty is related to calibration of the hydrological model. The total uncertainty associated with the prediction of groundwater levels remains large. By the end of the century, however, the uncertainty becomes smaller than the predicted decline in groundwater levels.
\end{abstract}

(c) 2015 Elsevier B.V. All rights reserved.

\section{Introduction}

Groundwater is an essential component of the water supply of several countries. It is also crucial for some specific groundwater dependent ecosystems. It is expected that water extraction from groundwater reserves will increase in some areas because of the foreseen increase in the water demand (Holman et al., 2012; Zhou et al., 2010). Long-term variations in temperature and precipitation, related to climate change, will also have an impact on future groundwater availability. Several studies have aimed at quantifying this impact for a variety of groundwater systems (e.g. Armandine Les Landes et al., 2014; Brouyère et al., 2004a; Goderniaux et al., 2009; Green et al., 2011; Herrera-Pantoja and Hiscock, 2008; Holman et al., 2012; Scibek et al., 2007; Van Roosmalen et al., 2009; Woldeamlak et al., 2007). These studies suggest that, compared to surface water, groundwater appears less

\footnotetext{
* Corresponding author.

E-mail address: Pascal.Goderniaux@umons.ac.be (P. Goderniaux).
}

vulnerable to extreme events such as droughts. This lower vulnerability is mainly explained by the significant water volumes stored in aquifers and that most often groundwater recharge occurs during periods that are longer than the typical duration of a drought. Its lower vulnerability makes groundwater a highly valuable water resource that is easier to distribute and manage.

Estimating the impact of climate change on groundwater reserves requires an adequate characterization of the concerned aquifers and robust modelling tools. Additionally, these estimations are affected by a series of uncertainties, such as the prediction of future greenhouse gas emissions and the uncertainty associated to climate and hydrological models. Quantifying these uncertainties is crucial to provide confidence intervals for predictions and therefore increase their credibility. Some of the previous studies have incorporated uncertainty analysis. For example, Ali et al. (2012), Jackson et al. (2011), Stoll et al. (2011), and Sulis et al. (2012) use input scenarios from more than one climate model (General Circulation Model - GCM or Regional Climate Model RCM), while others account for different greenhouse gas emissions 
scenarios (e.g. Dams et al., 2012; Neukum and Azzam, 2012; Serrat-Capdevila et al., 2007). The uncertainty analysis is, however, usually limited to the climatic part and uncertainty from other components, such as the hydrological model is often not estimated. Developing a numerical model always requires some level of a simplification of real systems and this simplification can have an impact on model predictions. Therefore, the ability of a model to satisfactorily reproduce reality, in accordance with the system's stresses, needs to be carefully evaluated.

The two main objectives of this paper are: (1) to estimate the uncertainty related to hydrological model projections in the context of climate change; and (2) to compare this source of uncertainty with sources of uncertainties related to the climate models (RCM and GCM), to the natural variability of the weather, and to the statistical downscaling method.

The different sources of uncertainties are considered for the Geer catchment $\left(465 \mathrm{~km}^{2}\right)$ in Belgium (Fig. 1), for which a catchment-scale fully-integrated surface-subsurface model has been developed. The parameterization of this hydrological model, a sensitivity analysis of the parameters, and the calibration of the model are presented in detail. The assessment of prediction uncertainty linked to this catchment-scale integrated model, the comparison with different sources of uncertainty, and the combination with advanced climate change scenarios bring new insights in the rising research on the impact of climate change.

\section{Previous studies}

The catchment-scale fully-integrated surface-subsurface model of the Geer basin has been developed with the finite element simulator HydroGeoSphere (Brunner and Simmons, 2012; Therrien et al., 2010). The modelling approach, involving the catchment-scale fully integrated surface-subsurface model, is described in Goderniaux et al. (2009). In Goderniaux et al. (2011), six RCMs were statistically downscaled and applied as input to the surface-subsurface hydrological model to quantify their impact on groundwater resources. These scenarios correspond to six contrasted Regional Climate Models (RCM) selected from the PRUDENCE ensemble. Their boundary conditions are taken from two different GCMs (see Fig. 2) and correspond to the SRES A2 (medium-high) greenhouse gas emissions scenario (Nakicenovic et al., 2000). As shown in Fig. 2, mean annual temperature changes ranging between $+3.5^{\circ} \mathrm{C}$ (HIRHAM_H) and $+5.6{ }^{\circ} \mathrm{C}$ (RCAO_E) are projected for the 2071-2100 period, as provided by the PRUDENCE project. All scenarios predict that temperature will increase and that the increase will be greater in summer than winter. The RCMs consistently project that annual precipitation will decrease for the 2071-2100 period but the predicted decrease ranges from $-1.9 \%$ (ARPEGE_H) to $-15.3 \%$ (HAD_P_H), which represents a large range of variation. The projected decrease in precipitation is a result of large projected decreases during summer months, which are only partly offset by increases in winter precipitation. These six RCMs were statistically downscaled using a stochastic weather generator (WG) (Blenkinsop et al., 2013), which considers changes in the climatic means and also in the distribution of wet and dry days. It allowed generating a large number of equiprobable climate change scenarios representative of a full transient climate between 2010 and 2085 (the middle of the 2071-2010 period). These scenarios accounted for the transient nature of future climate change, and enabled the assessment of

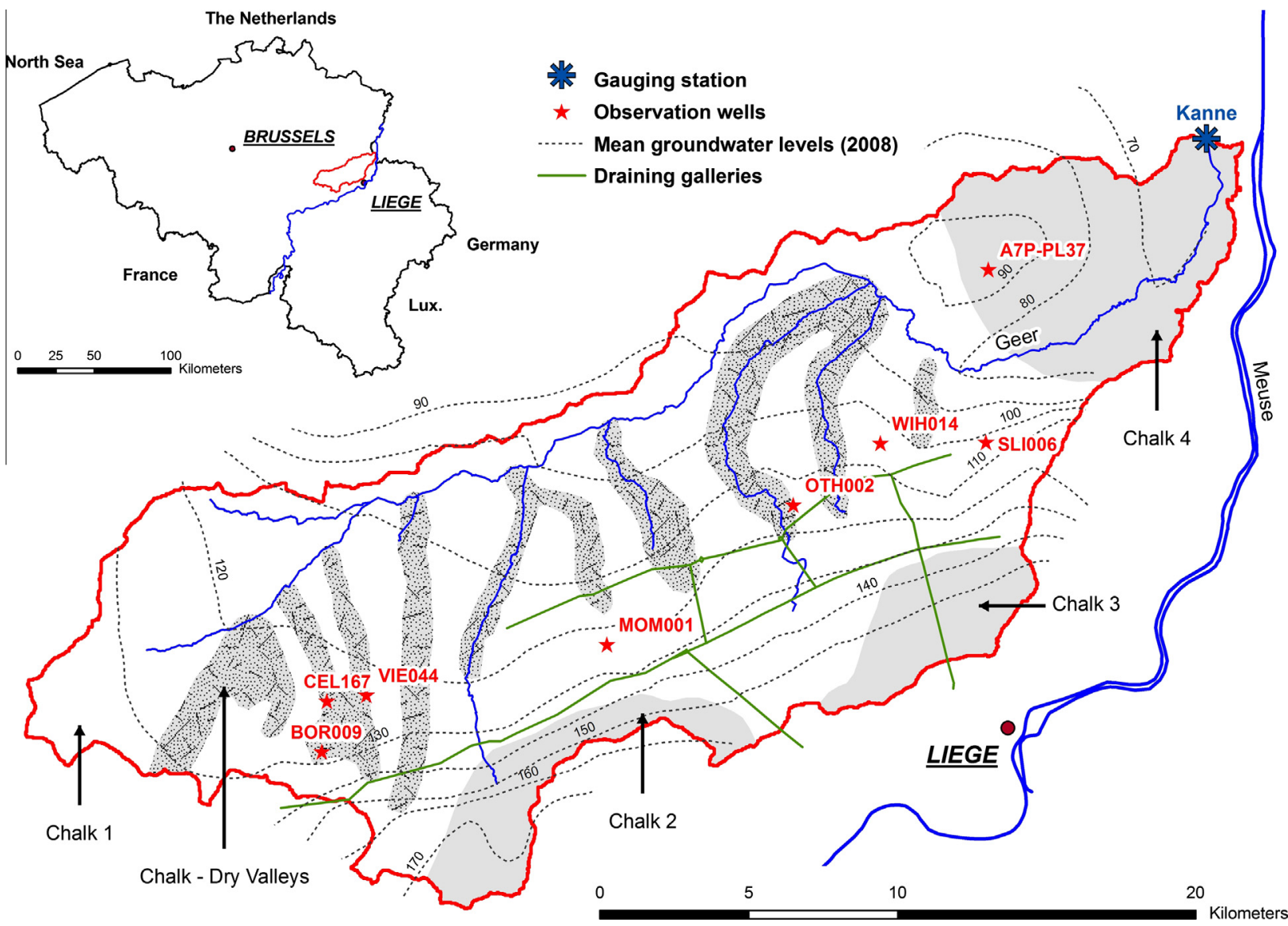

Fig. 1. Location of the Geer catchment in Belgium. The different zones correspond to different values of the hydraulic conductivity. 

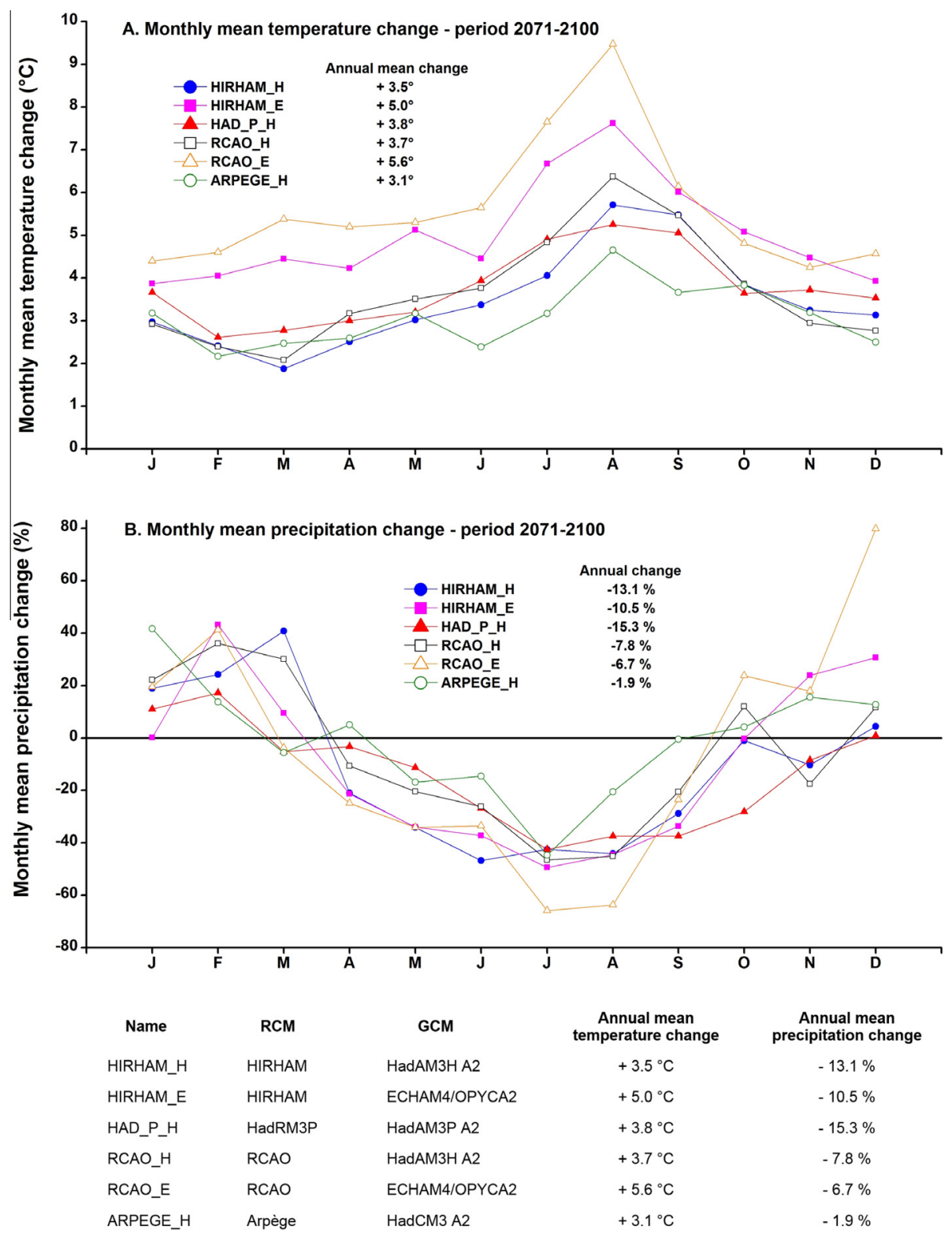

Fig. 2. Mean climatic changes for the A2 selected scenarios with corresponding RCMs and GCMs (modified from Goderniaux et al. (2009)).

the uncertainty related to the natural weather variability. Results have shown that by the year 2085 , depending on the climate model used and the location in the Geer basin, mean groundwater levels are expected to decrease by $7-20 \mathrm{~m}$ and water flow rates at the Geer basin outlet are expected to decrease between $44 \%$ and $70 \%$ compared to reference simulations without climate change.

\section{The Geer catchment}

The Geer catchment $\left(465 \mathrm{~km}^{2}\right)$ is located in eastern Belgium (Fig. 1). The main aquifer in the catchment consists of Cretaceous chalk layers. Groundwater is intensively extracted from the chalk aquifer from $70 \mathrm{~km}$ of draining galleries and additional pumping wells. This aquifer is considered to be a highly strategic groundwater reservoir as it supplies drinking water to about 600,000 people in the area of Liège city.

The chalk layers have a thickness that ranges from a few meters up to $70 \mathrm{~m}$ and they are underlain by a thick clay layer considered as impermeable. They are overlain by a thick layer of Quaternary loess over the whole area but they are also overlain by Tertiary sands in some local areas. The loess layer controls infiltration from the ground surface, which results in a smooth temporal distribution for groundwater recharge to the chalk aquifer (Brouyère et al., 2004a; Orban et al., 2010). The chalk aquifer has been characterized as a dual permeability and porosity system made of chalk porous matrix and fractures. Fracturing of the chalk is variable and more intense in dry valleys, which are mostly oriented South to North (Fig. 1). Groundwater generally flows from South to North and is mainly drained by the Geer River. Extracted groundwater volumes represent between $6 \%$ and $11 \%$ of annual precipitation. There is evidence of groundwater flow leaving the catchment across the Northern catchment boundary towards adjacent confined aquifers. This groundwater outflow was estimated around 7\% of annual precipitation for the period 1975-1994 (Hallet, 1998).

\section{The coupled surface and subsurface flow model}

The hydrological model applied to the Geer catchment simulates flow in the subsurface and surface domains and accounts for actual evapotranspiration. Hydrological variables, such as 
Table 1

List of the parameters used in the Geer catchment surface-subsurface hydrological model.

\begin{tabular}{lll} 
Subsurface domain & & \\
$K$ & Saturated hydraulic conductivity & $\left(\mathrm{L} \mathrm{T}^{-1}\right)$ \\
$n$ & Total porosity & $(-)$ \\
$\mathrm{Ss}$ & Specific storage & $\left(\mathrm{L}^{-1}\right)$ \\
$\alpha$ & van Genuchten parameter & $\left(\mathrm{L}^{-1}\right)$ \\
$\beta$ & van Genuchten parameter & $(-)$ \\
$S_{\mathrm{wr}}$ & Residual water saturation & $(-)$ \\
$S_{\text {Surface domain }}$ & & \\
$L_{c}$ & Coupling length & $(\mathrm{L})$ \\
$n_{x x}$ & Manning roughness coefficient & $\left(\mathrm{L}^{-1 / 3} \mathrm{~T}\right)$ \\
$n_{y y}$ & Manning roughness coefficient & $\left(\mathrm{L}^{-1 / 3} \mathrm{~T}\right)$ \\
$E_{v a p o t r a n s p i r a t i o n}$ & & \\
$L_{e}$ & & $(\mathrm{~L})$ \\
$\theta_{e 1}, \theta_{e 2}$ & Evaporation depth & $(-)$ \\
$\mathrm{LAI}$ & Evaporation limiting water content & \\
$L_{r}$ & (wilting point and field capacity) & $(-)$ \\
$\mathrm{C}_{1}, \mathrm{C}_{2}, \mathrm{C}_{3}$ & Leaf Area Index & $(\mathrm{L})$ \\
$\theta_{t 1}, \theta_{t 2}$ & Root depth & $(-)$ \\
$C_{\mathrm{int}}$ & Transpiration fitting parameters & $(-)$ \\
\hline
\end{tabular}

hydraulic head or surface water depth, are calculated simultaneously in each compartment and fluid exchange between compartments is calculated at each time step. All parameters used in the Geer catchment model are summarized in Table 1 and described below. The main equations solved by HydroGeoSphere are also provided in Appendix A.

HydroGeoSphere simulates 3D variably-saturated groundwater flow by solving Richards' equation with a control volume finite element numerical formulation. The chalk, loess and local sand layers are represented by 11 layers of 6 -node triangular prismatic elements whose typical size is about $500 \mathrm{~m}$ wide. The upper five layers, located just below ground surface, are one meter thick. The other six layers are uniformly distributed from the top to the bottom of the subsurface compartment. The top of the smectite clay layer is assumed to be the impermeable base of the chalk aquifer. The lateral boundaries of the model correspond to the hydrographical boundaries of the Geer catchment (Fig. 1). Piezometric maps suggest that the eastern, southern and western boundaries of the catchment correspond to groundwater divides and no-flow boundary conditions were therefore assigned to these boundaries. Groundwater outflow through the northern boundary is simulated with a head-dependent flux boundary condition that involves a conductance factor.

In the surface domain, HydroGeoSphere simulates 2D surface flow by solving the diffusion wave approximation of the SaintVenant equations. The lateral boundaries of the surface domain are similar to those of the subsurface. The surface domain is discretized with 2D triangular elements whose geometry corresponds to that of a layer of nodes for the 3D subsurface domain. Nodes that form the surface domain therefore coincide with the top layer of nodes that form the 3D subsurface domain. No-flow boundary conditions are assigned along the perimeter of the domain and a critical-depth boundary condition is prescribed at the nodes corresponding to the main catchment outlet in the Geer River. A critical-depth boundary condition forces the water elevation at the boundary to be equal to the 'critical depth', which minimizes the energy of flowing water relative to the stream bottom (Hornberger et al., 1998; Therrien et al., 2010). Water fluxes between corresponding surface and subsurface top layer nodes are included in the governing flow equations and they are based on the head difference between the two domains multiplied by a factor, which is inversely proportional to a coupling length $L_{c}[\mathrm{~L}]$ (Ebel et al., 2009). The value of these fluxes is therefore not assumed prior to a time step but rather computed during the fully coupled surface and subsurface flow simulation.

Subsurface parameters are distributed according to the different lithologies identified from geological and hydrogeological maps. The saturated hydraulic conductivity of the chalk is distributed in different layers and zones, defined on the basis of previous calibrated models and existing field and laboratory tests results (Brouyère et al., 2004a,b). The location and shape of these zones (Fig. 1) are mainly dependent on the properties of the fractures, which are more permeable within the dry valleys. Vertically, the hydraulic conductivity is generally lower for deeper chalk formations. The unsaturated flow properties of the different materials are represented with van Genuchten functions.

Surface and evapotranspiration parameters have been distributed based on land use and soil maps. Urban, crops, grassland and forested areas have been differentiated with different intervals of parameter values. Actual evapotranspiration is calculated by HydroGeoSphere according to the model of Kristensen and Jensen (1975), as a function of the potential evapotranspiration $E_{p}\left[\mathrm{~L} \mathrm{~T}^{-1}\right]$, and the soil moisture $\theta[-]$ at each node (see Appendix A).

Prescribed stresses correspond to precipitation, potential evapotranspiration, groundwater abstraction by draining galleries and pumping wells. The draining galleries and pumping wells are represented in the model with prescribed flow rate conditions. Precipitation and evapotranspiration are implemented as daily inputs. The transient values of the different variables of the model are calculated by HydroGeoSphere using adaptive time steps.

\section{Sensitivity analysis}

A sensitivity analysis of the model output to the input parameters is a crucial step as it increases the understanding of the model behaviour, helps assessing the reliability and relevance of field observations, and allows identifying possible conceptual or numerical errors. It also reduces simulation times for subsequent calibration, which is useful for catchment-scale models that are often computationally intensive. For example, insensitive parameters may be ignored in the calibration procedure as any change in their value will have very limited effect on target variables. Finally, sensitivities are needed to calculate subsequent uncertainties for predictions (see Section 7.1).

The sensitivity analysis for the Geer catchment model is performed with 'UCODE_2005' (Hill and Tiedeman, 2007; Poeter et al., 2005), linked to 'HydroGeoSphere', using the 'perturbation method'. Fig. 3 shows the 'Composite Scaled Sensitivity' (CSS) calculated for selected parameters using the following equation (Hill and Tiedeman, 2007).

$\mathrm{CSS}_{j}=\left(\frac{\sum_{i}^{N}\left(\frac{\partial y_{i}^{\prime}}{\partial b_{j}} \times\left|b_{j}\right| \times w_{i}^{1 / 2}\right)^{2}}{N}\right)^{1 / 2}$

$\mathrm{CSS}_{j}$ : Composite scaled sensitivity of parameter $j$

$y_{i}^{\prime}$ : Simulated variable $i$

$b_{j}$ : Parameter $j$

$w_{i}$ : Weight related to simulated variable $i$

$N$ : Number of selected simulated variables

where the weight $w_{i}$ that is assigned to each selected simulated variable accounts for the precision of equivalent observations measured in the field and is calculated with:

$w_{i}^{1 / 2}=\left(\frac{1}{\sigma_{i}^{2}}\right)^{1 / 2}=\frac{1}{\sigma_{i}}$ 


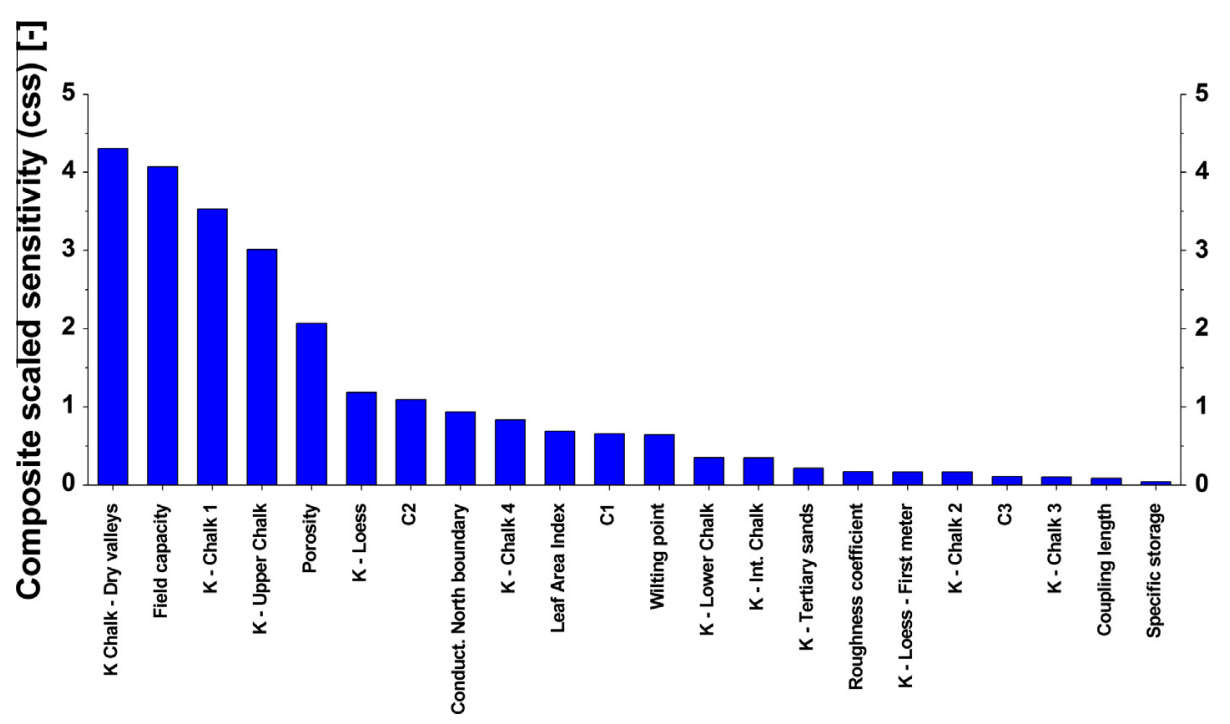

Fig. 3. Composite Scales Sensitivities (CSS) of the calibrated parameters of the Geer catchment model.

where $\sigma_{i}^{2}$ is the variance of the true measurement errors of observation $i$, corresponding to the simulated variable $i$. The CSS aggregates the sensitivities of selected simulated variables in relation to one parameter. In this case, the selected simulated variables correspond to monthly mean groundwater heads at eight observation wells and monthly mean surface flow rates at the outlet of the catchment (Fig. 1) for the period 1967-2003. Weighting the sensitivities by the inverse of the true measurement errors variance offers three main advantages (Hill and Tiedeman, 2007). (1) Weighted sensitivities are non-dimensional and can therefore be easily compared when corresponding variables have different units. (2) The weights also enable to integrate knowledge on the catchment through the uncertainty inherent to the observations. The weights calculated for unknown or inaccurately measured observations will be less important and will then reduce the influence of the associated sensitivity in the subsequent calibration or uncertainty analyses. (3) Finally, the weighting scheme is the basis of subsequent calibration and uncertainty analyses, as shown below in Sections 6 and 7.

The weight corresponding to the groundwater level observations are uniformly set to a value of 3.84. This value is based on the assumption that the $95 \%$ confidence interval including the true groundwater level is within $1 \mathrm{~m}$ of the measured groundwater level, considering all types of possible errors. These errors are related, for example, to the measurement of the well top elevation, measurement of the groundwater depth, the precision of the measurement devices and encoding errors. Assuming that measurement errors are normally distributed, the $95 \%$ confidence interval can be related to the variance. The weights associated to the surface water flow rates at the outlet of the catchment vary between 3.7 and 141.7. They have been calculated using measurement errors equal to $10 \%$, as suggested by the team responsible of measurements (personal communication) in the monitoring network.

The sensitivities shown in Fig. 3 correspond to the parameters that are used in the subsequent calibration procedure. Note that the values of the van Genuchten parameters have been fixed $a$ priori based on laboratory experiments (Brouyère et al., 2004b). These choices are further discussed in Section 8. To obtain a better understanding of the general functioning of the model, the sensitivity of some parameters are also calculated jointly for different zones or layers, by means of unity multipliers as suggested by Hill and Tiedeman (2007). UCODE_2005 perturbs the multiplier that acts simultaneously on parameter values in different zones, rather than to perturb all the parameter values of all zones individually. In this study, the sensitivity coefficients for hydraulic conductivity are calculated for each zone independently of the layer and for each layer independently of the horizontal zonation. As an example, the sensitivity of the hydraulic conductivities values assigned in the dry valleys ( $K_{\text {chalk_dry_valleys }}$ in Fig. 3 ) is calculated by perturbing a common multiplier, which acts simultaneously on the 'dry valley' hydraulic conductivities in all layers of the model. Similarly, the other sensitivity coefficients are generally calculated jointly for all zones of the model.

As shown in Fig. 3, the most sensitive parameters are the hydraulic conductivity of the 'dry valleys', the field capacity used to calculate the actual evapotranspiration, the hydraulic conductivity in the 'Chalk 1' zone (Fig. 1), the hydraulic conductivity in the upper chalk layer and the porosity (saturated water content) of the chalk. Parameters that show moderate sensitivity to observations include the hydraulic conductivity of the loess, parameters $\mathrm{C} 2$ and $\mathrm{C} 1$ used to calculate transpiration, the conductance used in the head-dependant flux boundary condition along the North boundary, the hydraulic conductivity in the 'Chalk 4' zone, the 'Leaf Area Index' and the wilting point. The remaining parameters show low sensitivity to observations.

\section{Calibration of the hydrological model}

Based on parameterization and the sensitivity analysis, the model was calibrated by trial-and-error to observed monthly mean hydraulic heads from the eight observation wells and to observed monthly surface mean flow rates at the catchment outlet (Fig. 1) for the period 1967-2003. Compared to Goderniaux et al. (2009), the model presented by Goderniaux et al. (2011) and in this paper was improved by using daily precipitation and evapotranspiration inputs instead of monthly inputs, leading to a different calibration of some parameters. The most sensitive parameters include the saturated hydraulic conductivities that range from $1 \times 10^{-8} \mathrm{~m} / \mathrm{s}$ for the Quaternary loess and $2 \times 10^{-4} \mathrm{~m} / \mathrm{s}$ for the chalk in dry valleys. The field capacity is equal to the saturation corresponding to a $\mathrm{pF}$ value - $\log$ (-hydraulic pressure) - equal to 2.5 , and the total porosity of the chalk (matrix and fractures) is equal to $44 \%$. The Manning roughness coefficients range from 0.03 to $0.6 \mathrm{~m}^{-1 / 3} \mathrm{~s}$. The other parameter values for the calibrated model are listed in Goderniaux et al. (2009). 
Fig. 4 presents, in different ways, the simulated and observed values for a global and objective assessment of the calibration. Fig. 4A shows corresponding simulated and observed mean monthly hydraulic heads and flow rates along with a line with a slope equal to 1 . Presenting calibration results in this fashion may not be adequate as the large ranges of simulated values tend to hide the possible calibration errors. Additionally, units and order of magnitude can also differ if different types of observation data are used in the calibration procedure. An alternative is to plot the residuals instead of computed values but it does not solve the problem of potentially different units. Hill and Tiedeman (2007) propose to use instead weighted residuals (Fig. 4B and C). For each observation, weighted residuals are calculated with the following equation:

$w r_{i}=w_{i}^{1 / 2} \times\left(y_{i}-y_{i}^{\prime}(\underline{b})\right)$ where $w r_{i}$ is the weighted residual corresponding to the simulated and observed values $i, y_{i}^{\prime}$ is the simulated variable $i, y_{i}$ is the observed variable $i$ corresponding to simulated variable $i, \underline{b}$ is the vector of parameters values and $w_{i}$ is the weight as defined in Eq. (2). As discussed in Section 5, using these weights enables: (1) comparison of non-dimensional values; (2) integration of the uncertainty related to observations; and (3) the performance of a subsequent uncertainty analysis. According to the results shown in Fig. 4, mean weighted residuals for hydraulic heads and flow rate observations are equal to -6.2 and 0.44 , respectively. This negative bias in the simulated groundwater levels is mainly due to the simulated groundwater levels at well A7-PL37. At that location, observed groundwater levels are significantly underestimated due to the proximity of the boundary condition, which may be uncertain locally. For the other observation points, weighted residuals are generally distributed around zero.
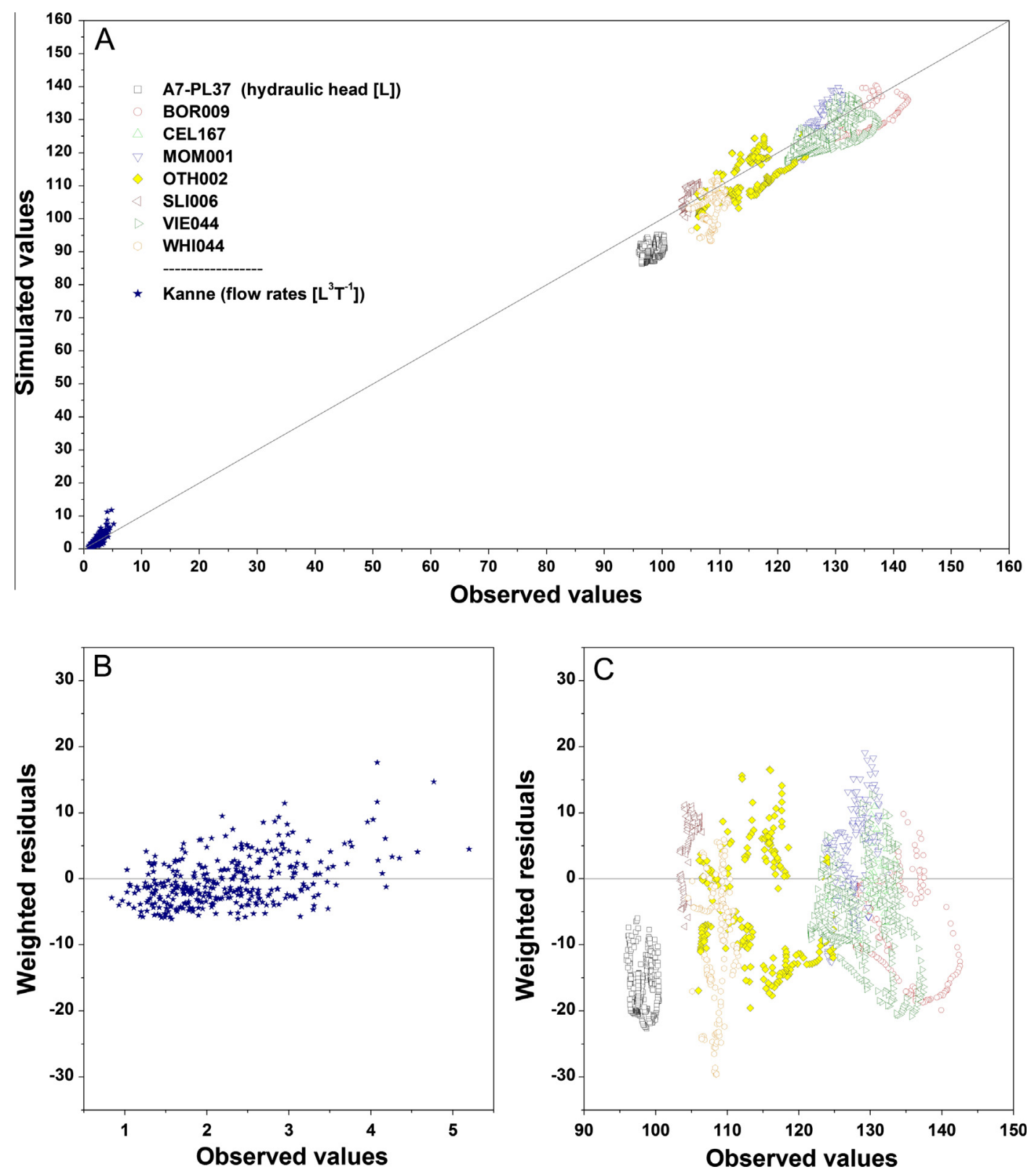

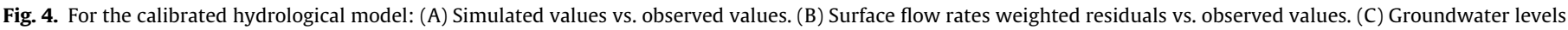
weighted residuals vs. observed values. 


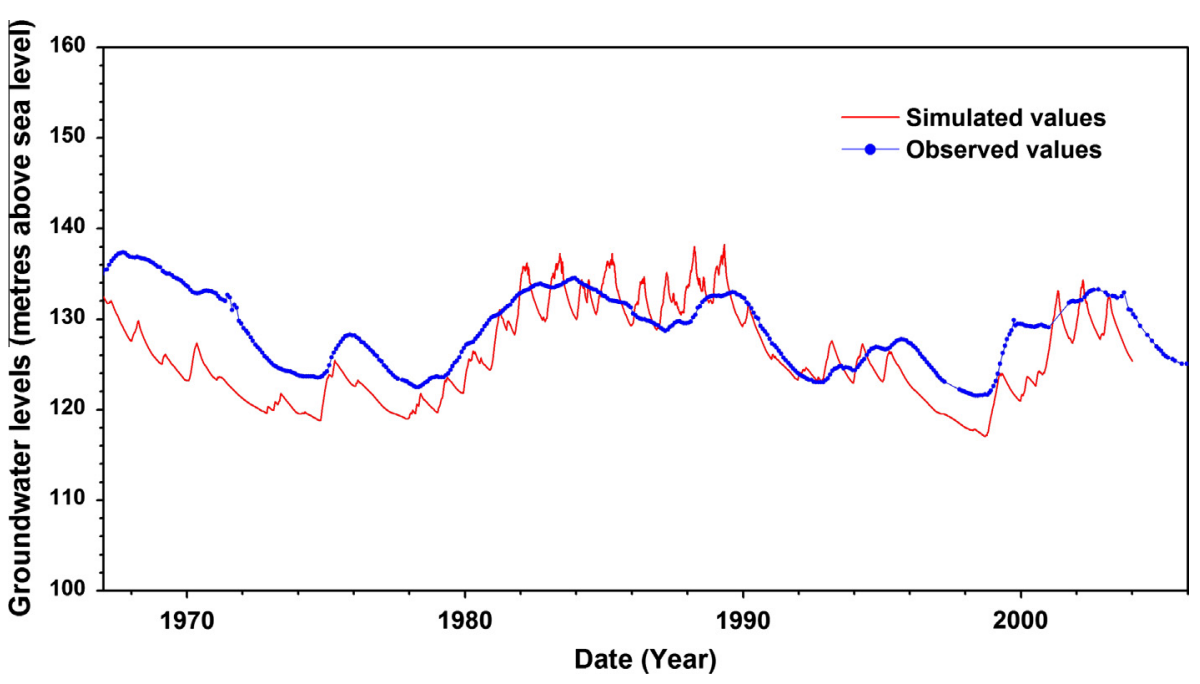

Fig. 5. Temporal evolution of observed and simulated groundwater levels at observation well 'VIE044'.

These results can be examined in parallel to the observed and simulated time series. Fig. 5 shows the evolution of observed and simulated groundwater levels at piezometer 'VIE044'. The observed time series reflects the typical evolution of groundwater levels in the catchment, with large multi-annual rather than seasonal variations. Observed groundwater levels in 'VIE044' range between $122 \mathrm{~m}$ and $138 \mathrm{~m}$ above sea level, which corresponds to a total variation of $16 \mathrm{~m}$. Fluctuations are on the same order at other observation points, with less variation closer to the river. Residual values (Fig. 4) have to be considered keeping in mind these important natural variation intervals. The multi-annual variations of observed hydraulic heads are generally reproduced by the model, and the water balance of the system is well fitted. However, the model generally tends to overestimate surface water flows and groundwater levels during 'high flow' periods and to underestimate them during 'low flow' periods. This is also visible in Fig. 4B for surface flow rates, with higher weighted residuals for higher flow rates.

\section{Uncertainty analyses on predictions}

In this section, the uncertainty related to the calibration of the hydrological model is evaluated and compared to: (1) the uncertainty related to climate models and their statistical downscaling procedure; and (2) the uncertainty related to natural variability of local weather. The uncertainty related to the calibration of the hydrological model is presented in Section 7.1, Figs. 6 and 7. The uncertainties related to climate models and natural variability of the weather were already evaluated in Goderniaux et al. (2011) and they are briefly summarized in Section 7.2. The three types of uncertainties, as well as results related to two different climate downscaling methods, are shown and compared in Table 2, in Fig. 8 for groundwater levels, and in Fig. 9 for the surface flow rates at the outlet of the catchment.

\subsection{Uncertainty related to the calibration of the hydrological model}

Calibration of a model does not guarantee that it will make accurate predictions. For example, a model calibrated to reproduce observations under specific conditions may provide poor predictions for a different set of stresses (Henriksen et al., 2003; Hill and Tiedeman, 2007; Konikow and Person, 1985; Refsgaard, 1997). That situation is typical for climate change simulations where model predictions are based on future precipitation and potential evapotranspiration values that are different from those used to calibrate the model.

The prediction uncertainty linked to model calibration is quantified here using an inferential statistical method described in detail in Hill and Tiedeman (2007). Other methods exist but are generally more computationally intensive. The inferential statistical method used here relies on the statistics describing the model fit to observations and the results of the sensitivity analysis to evaluate the uncertainty related to estimated parameters and
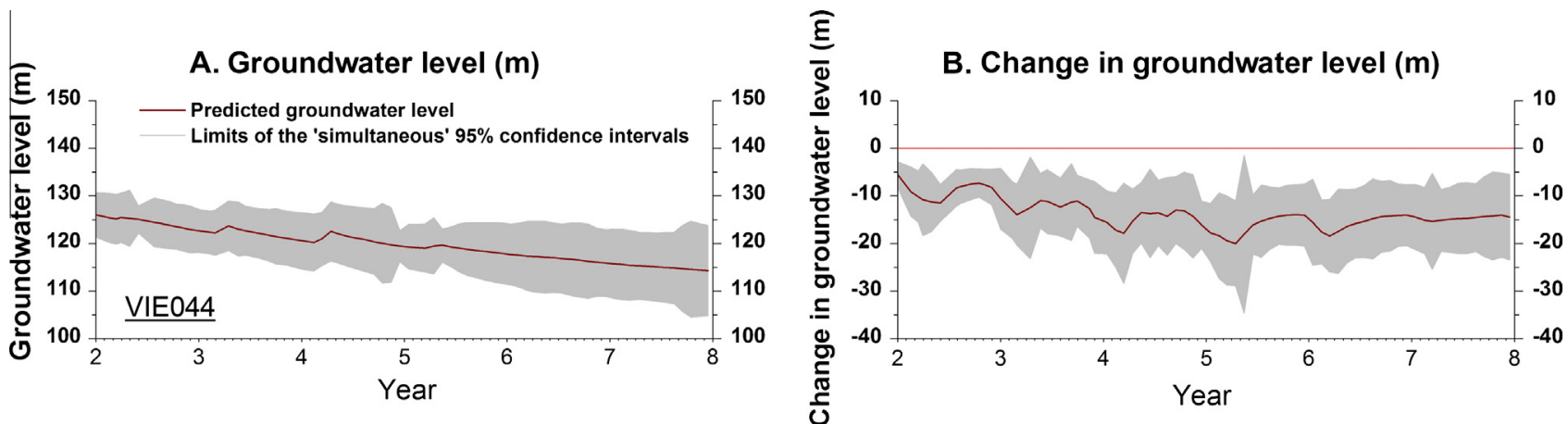

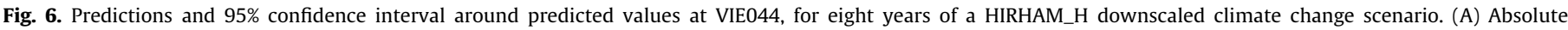
groundwater levels. (B) Groundwater levels difference between a scenario without any climate change and the HIRHAM_H climate change scenario. 

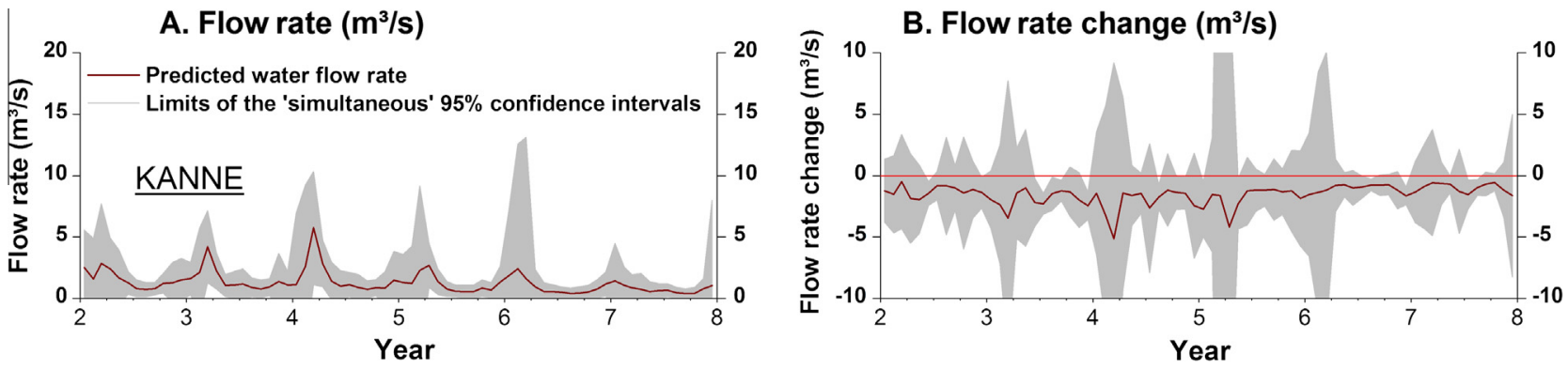

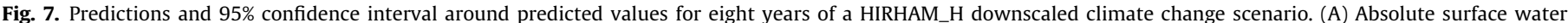
monthly flow rates. (B) Difference in surface water monthly flow rates between a scenario without any climate change and the HIRHAM_H climate change scenario.

Table 2

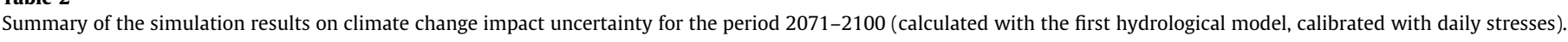

\begin{tabular}{|c|c|c|c|c|}
\hline Type of uncertainty & Method & Type of interval calculated & $\begin{array}{l}\text { Interval width } \\
\text { for groundwater } \\
\text { levels at the eight } \\
\text { observation wells } \\
\text { (Min-Max) (m) }\end{array}$ & $\begin{array}{l}\text { Interval width for } \\
\text { annual flow rates } \\
\text { (catchment outlet) } \\
\text { (Min-Max) }\left(\mathrm{m}^{3} / \mathrm{s}\right)\end{array}$ \\
\hline Natural variability of the weather & Use of 180 equiprobable climatic scenarios & $95 \%$ confidence interval & $2.3-18.6$ & $1.01-2.55$ \\
\hline Climate models & Use of six RCMs experiments & Total range of variation & $3.2-11.3$ & 0.99 \\
\hline Calibration of the hydrological model & Inferential statistical methods ('UCODE_2005') & $95 \%$ linear confidence interval & $6.9-28.7$ & 3.92 \\
\hline Downscaling method & Use of two different downscaling methods & Total range of variation & $0.7-4.8$ & $0.05-0.35$ \\
\hline
\end{tabular}

predictions. The analyses were performed with the computer code 'UCODE_2005' (Hill and Tiedeman, 2007).

Using this method, 95\% linear confidence intervals around predictions can be calculated. It is assumed that the model is linear in the vicinity of parameter values and, more particularly, that parameter sensitivities are constant within calculated intervals. This assumption is further discussed in Section 8.

For the Geer catchment model, the objective is to evaluate the uncertainty of predicted groundwater levels and flow rates associated with the calibrated hydrological model, under climate change conditions. For that purpose, the calibrated model was run for an 8 -year period using climatic conditions representative of the time period 2071-2100 and the RCM 'HIRHAM_H' (Fig. 2). 'HIRHAM_H' can be considered as a medium climate change scenario compared to the other RCMs. The prediction uncertainty is evaluated for mean monthly groundwater levels simulated at eight observation wells and for simulated surface flow rates at the outlet of the catchment. For the same 8-year period, the uncertainty is also calculated for the difference between the predicted groundwater levels and flow rates and the levels and flowrates simulated with equivalent climatic time series but without climate change. Although the simulation is for an 8-year period, uncertainty is only evaluated after two years of simulation, from year 2 to year 8 , because initial conditions influence the model results during the first two years. These aspects are further discussed in Section 8. Weighting values are similar for the sensitivity and calibration analyses (Sections 5 and 6).

Resulting 95\% confidence intervals for years 2-8 are presented in Fig. 6 for groundwater levels at the observation well 'VIE004' and in Fig. 7 for surface water flow rates at the outlet of the catchment. They correspond to the 'Simultaneous confidence intervals', which have the specified probability to contain their respective true predicted values, considering all predictions simultaneously (Hill and Tiedeman, 2007). Mean 95\% confidence intervals for groundwater levels at all observation wells and surface flow rates at the outlet of the catchment are presented by green intervals in Fig. 8 and Fig. 9, respectively. The mean range of the 95\% confidence intervals around simulated groundwater levels varies between $6.9 \mathrm{~m}$ at observation well A7-PL37 and $28.9 \mathrm{~m}$ at MOM001. Generally, the range of the confidence intervals around predicted values (Fig. 6A) has the same order of magnitude than the range of equivalent intervals around predicted changes (Fig. 6B). The intervals around predicted changes are significant but entirely located in the negative part of the graph (Fig. 6B). Although some variations in the range of these intervals are observed during the 6-year period, there is no clear trend for most of the observation wells. The mean $95 \%$ interval for surface water flow rates is equal to $3.9 \mathrm{~m}^{3} / \mathrm{s}$. The intervals are however larger for winter than for summer, as shown in Fig. 7A, corresponding to a greater uncertainty when flow rates increase. This greater uncertainty is mainly explained by the poorer calibration of simulated flow rates during 'high-flow' periods, and the fact that these errors translate into predictions.

\subsection{Comparison of uncertainties}

The impact of climate change for the six RCMs and the uncertainty related to natural weather variability has been evaluated from a large number of equiprobable climate change scenarios generated with the rainfall model RainSim (Burton et al., 2008) and the 'CRU daily weather generator' downscaling technique (Kilsby et al., 2007). One hundred equiprobable climate change scenarios, representative of fully transient climate change conditions from 2010 to 2085, have been generated for each of the six RCMs, and then applied to the calibrated hydrological model (Goderniaux et al., 2011). These climate change time series have been achieved using the relative changes between the RCM simulations representative of a stationary climate for the periods 19611990 (control) and 2071-2100 (future). Reference time series without any climate change were also generated.

Using the whole set of simulated values, the predicted mean groundwater levels at the observation wells and the predicted mean flow rate at the Geer catchment outlet were calculated. Mean predicted values for the year 2085 (or equivalently for the 

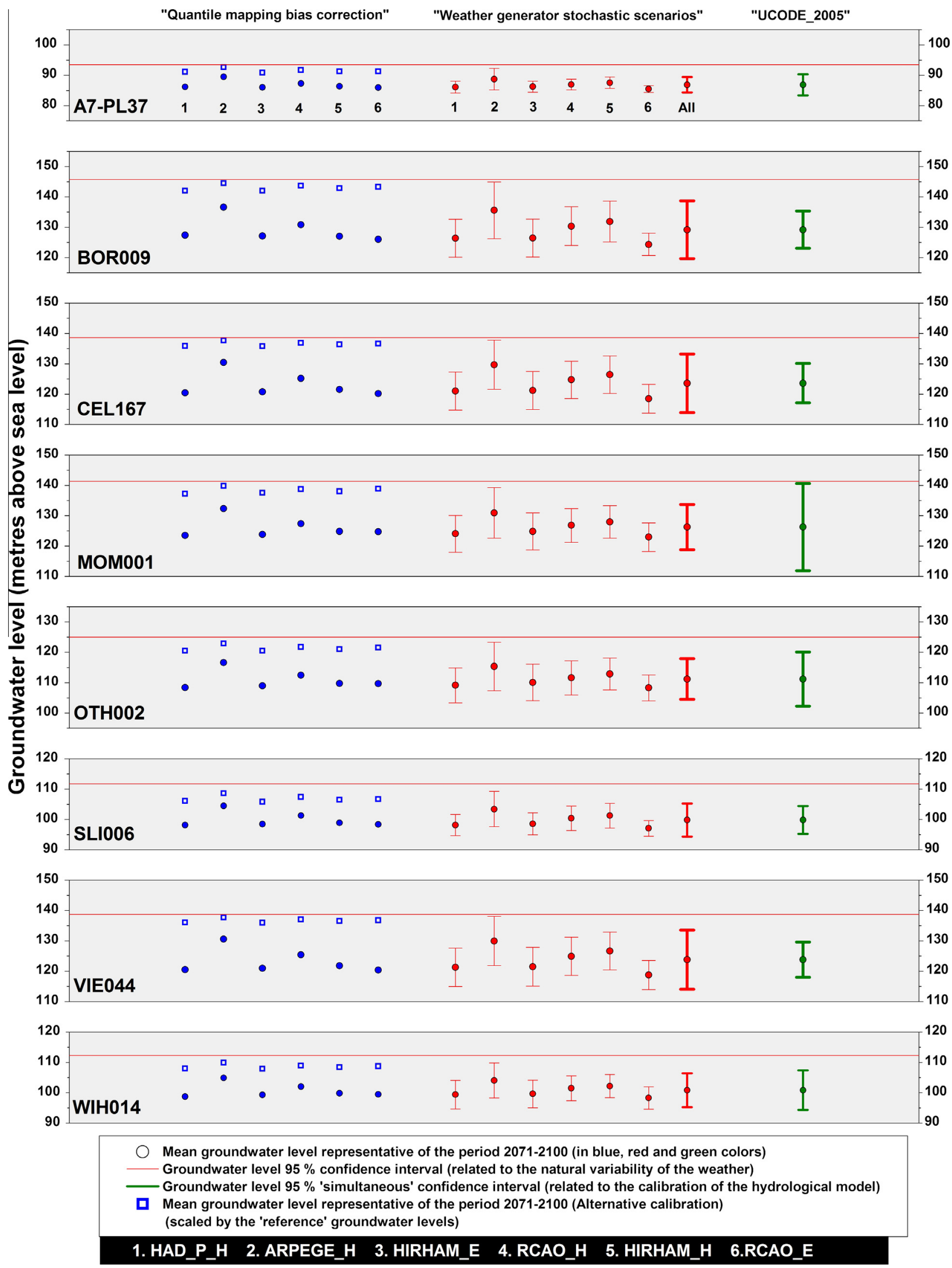

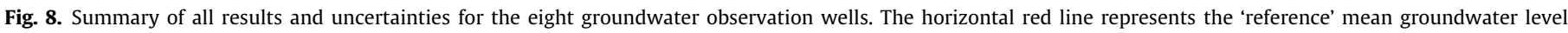
without any climate change. (For interpretation of the references to colour in this figure legend, the reader is referred to the web version of this article.) 

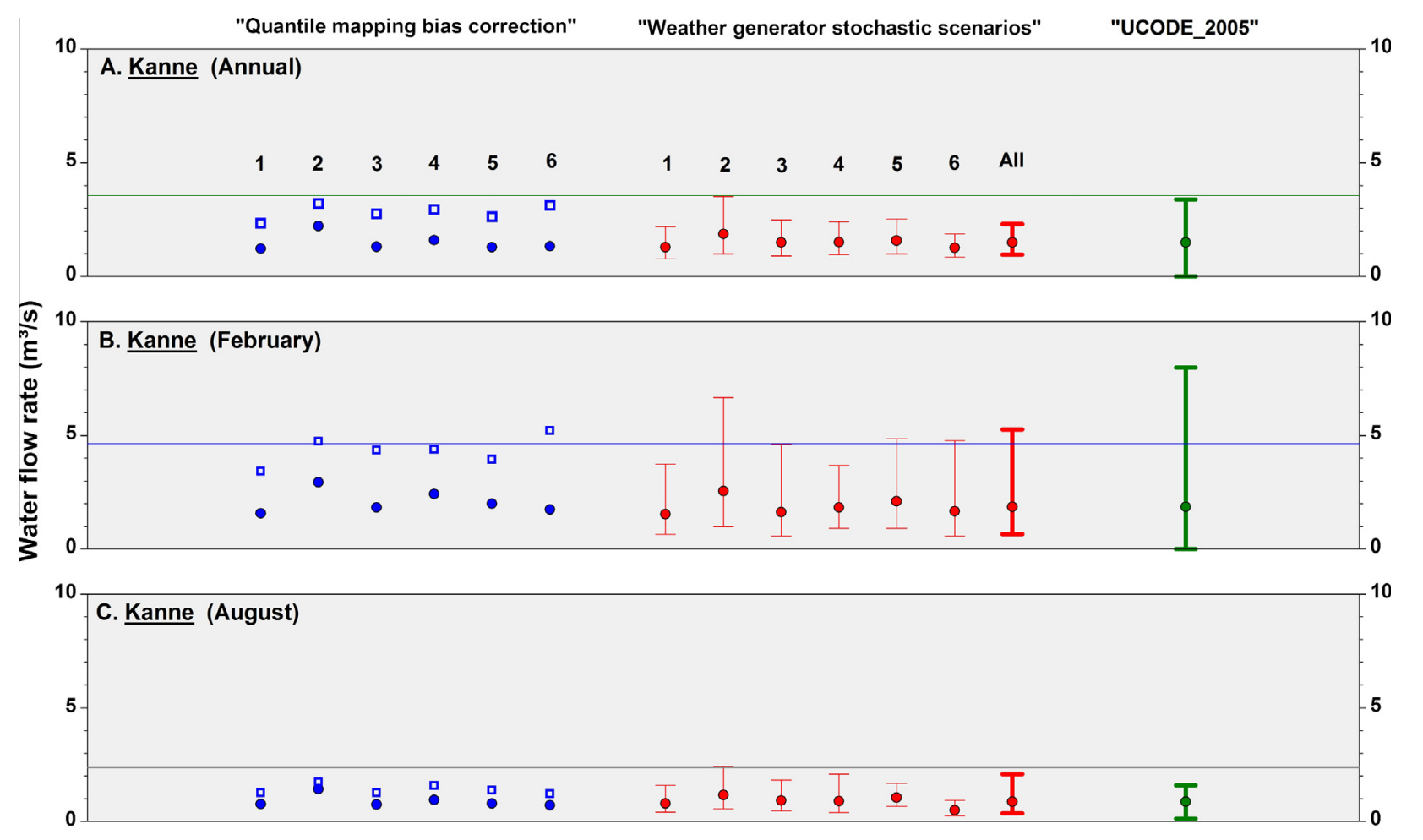

Mean flow rate representative of the period 2071-2100 (in blue, red and green colors)

Flow rate $95 \%$ confidence interval (related to the natural variability of the weather)

Flow rate $95 \%$ 'simultaneous' confidence interval (related to the calibration of the hydrological model)

Dean flow rate representative of the period 2071-2100 (Alternative calibration)

(scaled by the 'reference' flow rates)

1. HAD_P_H 2. ARPEGE_H 3. HIRHAM_E 4. RCAO_H 5. HIRHAM_H 6.RCAO_E

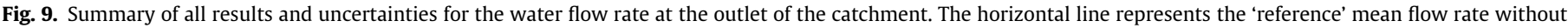
any climate change.

stationary climate representative of the period 2071-2100) are shown with red dots in Figs. 8 and 9 for the six different climate models considered. Depending on the climate model used and the location of the observation well in the Geer catchment, mean groundwater levels are expected to decrease by 7-20 m, and water flow rates at the Geer catchment outlet are expected to decrease between $44 \%$ and $70 \%$ compared to the reference simulations without climate change. The highest and lowest decreases are usually predicted for the 'HAD_P_H' and 'ARPEGE_H' scenarios, respectively. Some of these impacts are important but they have the same order of magnitude than the natural fluctuation interval (up to $16 \mathrm{~m}$ in VIE044) observed on groundwater levels time series.

The whole set of simulated groundwater levels and flow rates was also used to calculate $95 \%$ confidence intervals, related to the natural variability of weather (Goderniaux et al., 2011), for groundwater levels and flow rates. They are shown with the red intervals in Figs. 8 and 9, respectively. At the end of the simulation, corresponding to year 2085, the range of the confidence interval for groundwater levels varies between $2.3 \mathrm{~m}$ and $18.6 \mathrm{~m}$, depending on the location of the observation well and the climate model used. The range of the confidence intervals for the annual flow rates at the outlet vary between 1.01 and $2.55 \mathrm{~m}^{3} / \mathrm{s}$, depending on the climate model (Fig. 9). The confidence intervals for the mean monthly flow rates are larger during winter than during summer. The range of confidence intervals tends to decrease where the partially saturated zone becomes thicker and attenuates meteorological events.

Additional results shown with blue dots in Fig. 8 and Fig. 9 are groundwater levels and surface flow rates predicted with the calibrated hydrological model described here but for climate data predicted with the 'Quantile Mapping Bias Correction'. It is an alternate technique for statistical climate downscaling described in Wood et al. (2004) and already applied in Goderniaux et al. (2009). This technique, and the 'weather generator' method used previously, are considered more reliable than simplistic 'delta change' methods because they involve corrections not only to the mean of climatic variables but also across their statistical distribution. However, the 'Quantile Mapping Bias Correction' does not generate stochastic equiprobable time series, which is possible with the 'weather generator', and therefore a single result is shown for each climate model. A visual comparison of predicted groundwater levels (Fig. 8) and flow rates (Fig. 9) for the 'Quantile Mapping Bias Correction' (blue dots) and the 'weather generator' (red dots) indicate that the differences are smaller than the confidence intervals of other uncertainty sources. Table 2 also lists the main results from these simulations.

Finally, blue squares in Figs. 8 and 9 show climate change impact results for a different calibrated hydrological model than presented previously, and based on climate data generated with the 'Quantile Mapping Bias Correction'. This second calibrated model is presented in detail in Goderniaux et al. (2009). The conceptual model is the same but an important difference is that monthly weather inputs were used instead of daily inputs, leading to a different calibration of some parameters. This model clearly predicts lower decreases in both groundwater levels and surface water flow rates for the period 2071-2100. The uncertainty associated to these results have not, however, been evaluated in this study. The differences in projected impacts between both models 
results from the different calibration of the hydrogeological model. The second calibration globally overestimates groundwater levels while underestimating groundwater variations. The first calibration (described in this present paper) tends to overestimate groundwater level variations. These results suggest that the 'best' calibration might be intermediate between both models. This reasoning is however speculative and based on simplistic assumptions, which must be verified by a more detailed uncertainty analysis.

Simulation results shown in Figs. 8 and 9 indicate that uncertainties related to the calibration of the hydrological model (green interval) and to the natural variability of the climate (red intervals) appear to be the most important. The uncertainty related to the use of different GCMs and RCMs is less significant. These different types of uncertainties can be classified into two groups. First, the uncertainty related to natural variability of climate is inherent to meteorological events and therefore unavoidable. Calculated intervals do not reflect any model 'error' but instead express how groundwater levels or surface water flow rates will inevitably vary with time around an average position, due to the occurrence of dry and wet periods. It is an expression of natural groundwater fluctuations in the catchment, as impacted by climate change, and by enhanced smoothing of the individual meteorological events resulting from the occurrence of a thicker unsaturated zone overlying the aquifer. The second source of uncertainty is related to 'errors' or 'approximations' made in climate or hydrological modelling. These uncertainties can be reduced by improving models and knowledge required for their implementation. If the conceptual model is correct and the calibration strategy prevents from fitting observation errors, a model that better fits the observations should also give more confident predictions.

Significant decreases of groundwater reserves are predicted over the whole catchment for the simulation period, but the ranges of the confidence intervals remain large compared to the projected decreases. However, the confidence intervals or ranges of variations (Fig. 8) remain mostly below the 'reference' groundwater level corresponding to the 1980s climate without any change. It is therefore likely that groundwater levels will decrease by the end of the century, due to climate change, but the magnitude of decrease cannot be quantified accurately. Similarly, it is difficult to accurately predict the annual flow rates at the outlet of the catchment. However, at a seasonal scale, the uncertainty is larger for winter flow rates than for summer flow rates, with the uncertainty also spreading in the area corresponding to flow rates increase (Fig. 9).

\section{Discussion and perspectives}

This study is original as it provides new insights in the evaluation of climate change impact on groundwater, from data collection, the implementation of catchment-scale surface-subsurface models, and the evaluation and comparison of several types of uncertainties. Results provide estimates and orders of magnitude of the different uncertainties and they give an idea of the confidence we can have in simulated predictions. Using this methodology gives credibility to the predictions and allows using probabilities to manage the resource. The methodology used here, however, relies on a series of assumptions that could be verified in the future with improved computational resources and numerical algorithms. Some of these assumptions are discussed below.

Linear confidence intervals have been calculated around predictions. These intervals assume that the model is linear in the vicinity of parameter values and that parameter sensitivities are constant within the calculated intervals. This condition is probably not met in all cases, especially when the overall system becomes "dryer" as can be observed in Fig. 7A. In that case, confidence intervals sometimes spread in the negative part of the graph (hidden in Fig. 7A), leading to potentially negative water flow rates, which is unrealistic. This result is due to the strong non-linear behaviour of the system when flow rates are very low. Methods exist to calculate non-linear confidence intervals around predictions (Hill and Tiedeman, 2007; Vecchia and Cooley, 1987). However, as the automatic inverse calibration methods, they are computationally very intensive. Their use in conjunction with coupled surface and subsurface flow models, which are also computationally demanding, still has to be demonstrated.

Linear confidence intervals are usually calculated following a successful termination of an automatic inverse calibration. Ideally, weighted residuals should be randomly distributed around zero which is not the case for the observation well A7-PL37, whose residuals are biased. In this case, the influence of A7-PL37 on predictions uncertainties seems quite local, as suggested by low parameters sensitivities to groundwater levels at this specific point. Nevertheless, the range of calculated confidence intervals for this particular observation point should probably be considered with caution.

The uncertainty related to the calibration of the hydrological model has been calculated under climate change conditions of the RCM 'HIRHAM_H', which presents medium climate change conditions compared to others, and for a predictive period of eight years. We assume that the range of confidence intervals associated to predictions would probably be similar under climate conditions of the five others RCMs, but it remains to be verified. Similarly, the mean uncertainty is calculated over predictive periods of eight years, mainly to reduce computing times. During this period, no trend in the range of the confidence interval is observed, but longer periods could be tested.

Finally, other sources of uncertainty have not been considered in this study. All climatic scenarios used here correspond to the A2 greenhouse gas emissions scenario (medium-high) (Fig. 2). So, climate change impact and uncertainties have been evaluated considering greenhouse gas emissions for that scenario. Considering lower emissions, such as the B2 scenarios (mediumlow), would lead to less important changes. Déqué et al. (2007) showed, however that when using climate models, the uncertainty from emissions scenarios was lower than the uncertainty from GCMs and RCMs over Belgian latitudes. Another uncertainty not considered in this study is linked to the conceptual model used when implementing the hydrological model. This uncertainty relates to potential changes that would be induced by other boundary conditions, different numbers of finite elements in the grid or alternative zonation of the hydraulic properties, for example. The evaluation of such uncertainty has been studied by Rojas (2009) and Rojas et al. (2009) for a regional aquifer in Chile, but not in the context of climate change impact. Following these considerations related to the conceptual choices, the parameterisation of the hydrological model and the parameters integrated in the uncertainty analysis also influence the uncertainty. In this study, the values of the van Genuchten parameters have been taken from laboratory experiments (Brouyère et al., 2004b). They were not considered as adjustable in the calibration procedure and in the uncertainty analysis. However, their sensitivities are probably significant (Wildemeersch et al., 2014). It does not mean necessarily that they would have significantly influenced the range of the confidence intervals, as the most sensitive parameters are also generally better calibrated. Nevertheless, integrating them into the uncertainty analysis could slightly alter related results.

This study also highlights the question about developing simple or complex models. More complex models may allow more realistic simulations, if more detailed about geology and hydrogeology are available. However, the calibration and uncertainty analysis 
also require more computational capacities. As a consequence, studies probably have to find a good compromise between oversimplified and too complex models, as a function of the final objectives of the simulations and the available resources.

\section{Conclusions}

This study presents an evaluation of uncertainties related to catchment-scale integrated hydrological models and climate change impacts on groundwater. Results have shown the importance of considering and comparing different sources of uncertainty, and particularly to assess the uncertainty related to the calibration of the hydrological model. This type of uncertainty can be more important than others, as illustrated by the case of the Geer catchment and related models, presented in this study. In this case, the uncertainty related to the calibration of the hydrological model and, to a lesser extent, the climate models, remain important. It is therefore difficult to accurately quantify the intensity of the mean groundwater level and surface flow rate changes. Nevertheless, the trend towards a general decrease of mean groundwater level is calculated with more confidence, which was initially not obvious or straightforward. In the Geer catchment, recharge mainly occurs during winter months. During these periods, the frequency of wet and dry days is expected to change, and the expected increase in temperature and evapotranspiration is offset by an increase in precipitation, making the analysis complex. If better precision is required for predictions, improving the calibration of the hydrological model would contribute to decrease uncertainty. Note that the intervals related to the natural variability of the weather are not directly linked to models errors, but express how predicted groundwater levels and surface flow rates are expected to vary around their mean value, considering the hydrological model used.

Evaluation of these uncertainties remains challenging for catchment-scale impact studies. Challenges relate to the complexity of the simulated processes, the availability of data, the size of models and lengthy computing times, which constrain the number and length of model runs, as well as the use of particular methods. Improvements in modelling tools and computing resources should will provide new possibilities for this type of study. Nevertheless, the methodology used here allows to analyse more objectively the simulated impacts of climate change on groundwater, and these results could constitute a guide in the arduous and difficult task of uncertainty analysis in this context.

\section{Acknowledgements}

This work was supported by the European Union FP6 Integrated Project AquaTerra (Project $n^{\circ}$ 505428) under the thematic priority sustainable development, global change and ecosystems. Observed climatic data have been provided by the 'Royal Institute of Meteorology of Belgium'. RCM data have been provided through the PRUDENCE data archive, funded by the EU through contract EVK2-CT2001-00132. Pascal Goderniaux was funded by FNRS during the period 2006-2010.

\section{Appendix A}

\section{A.1. Subsurface equations}

Three-dimensional groundwater flow in both the saturated and the unsaturated zone is represented using Richards' equation.

$-\nabla \cdot \boldsymbol{q}+\sum \Gamma_{\mathrm{ex}} \pm Q=S_{w} S_{s} \frac{\partial \Psi}{\partial t}+\frac{\partial\left(\Phi S_{w}\right)}{\partial t}$ where $\Gamma_{\mathrm{ex}}$ is the volumetric fluid exchange rate between the subsurface domain and the other domains within the model [T-1], $Q$ is a source/sink term $\left[\mathrm{T}^{-1}\right], S_{s}$ is the specific storage $\left[\mathrm{L}^{-1}\right], \Psi$ is the pressure head [L], $\Phi$ is the porosity [-], and $S_{w}$ is the water saturation [-]. The fluid flux $q[\mathrm{~L} \mathrm{~T}-1]$ is calculated as:

$\mathbf{q}=-\boldsymbol{K} k_{r} \nabla h$

where $K$ is the hydraulic conductivity tensor $\left[\mathrm{L} \mathrm{T}^{-1}\right], k_{r}$ is the relative permeability of the medium [-], and $h=\Psi+z$ is the hydraulic head [L], and $Z$ is the elevation head [L].

The relations linking water saturation, pressure head, and relative permeability are expressed using the model of van Genuchten.

The saturation-pressure relation proposed by van Genuchten is written:

$S_{w}=S_{\mathrm{wr}}+\left(1-S_{\mathrm{wr}}\right)\left[1+\left|\alpha_{v G} \Psi\right|^{\beta_{v G}}\right]^{-\gamma_{v G}}$ for $\Psi<0$

$S_{w}=1$ for $\Psi \geq 0$

The relative permeability $k_{r}$ is given by:

$$
\begin{aligned}
& k_{r}=S_{e}^{1 / 2}\left[1-\left(1-S_{e}^{1 / \gamma_{v G}}\right)^{\gamma_{v G}}\right]^{2} \\
& S_{w}=\frac{\theta}{\Phi} \text { : Water saturation (-) } \\
& \theta \text { : Water content (-) } \\
& S_{e}=\frac{S_{w}-S_{\mathrm{wr}}}{1-S_{\mathrm{wr}}} \text { : Effective saturation (-) } \\
& S_{\mathrm{wr}} \text { : Residual water saturation (-) } \\
& \alpha_{v G}[L-1], \beta_{v G}[-] \text {, and } \gamma_{v G}[-] \text { : Van Genuchten parameters } \\
& \gamma_{v G}=\left(1-\frac{1}{\beta_{v G}}\right)
\end{aligned}
$$

\section{A.2. Surface equations}

Two-dimensional surface water flow is represented using the two-dimensional depth-averaged diffusion-wave approximation to the Saint-Venant equation:

$-\nabla \cdot\left(d_{s} \boldsymbol{q}_{s}\right)-d_{s} \Gamma_{s} \pm Q_{s}=\frac{\partial\left(h_{s}\right)}{\partial t}$

where $d_{s}$ is the depth of the surface water flow [L], $h_{s}=d_{s}+z_{s}$ is the water surface elevation [L], and $z_{s}$ is the river bed elevation [L], $\Gamma_{s}$ is the volumetric fluid exchange rate between the surface domain and the other domains within the model $\left[\mathrm{T}^{-1}\right], Q_{s}$ is the source/sink term $\left[\mathrm{T}^{-1}\right]$. The fluid flux $q_{s}\left[\mathrm{LT}^{-1}\right]$ is calculated as:

$\mathbf{q}_{\boldsymbol{s}}=-\boldsymbol{K}_{\boldsymbol{s}} \nabla\left(d_{s}+z_{s}\right)$

where $k_{r s}$ is the relative permeability of the surface water domain. The conductivity $K_{s}$ is derived using the Manning's formula:

$K_{s x x}=\frac{d_{s}^{\frac{2}{3}}}{n_{x x}} \frac{1}{\left(\partial h_{s} / \partial s\right)^{\frac{1}{2}}}$

$K_{s y y}=\frac{d_{s}^{2 / 3}}{n_{y y}} \frac{1}{\left(\partial h_{s} / \partial s\right)^{1 / 2}} K_{s x y}$

$K_{\text {sxy }}=K_{\text {syx }}=0$

where $s$ is the length along the direction of maximum slope [L], and $n_{x x} a n d n_{y y}$ are the Manning roughness coefficients $\left[\mathrm{L}^{-1 / 3} \mathrm{~T}\right]$.

The interactions between groundwater and surface water are simulated using an exchange flux relation:

$d_{s} \times \Gamma_{s}=\frac{k_{r} \times K_{z z}}{L_{c}} \times\left(h-h_{s}\right)$

where $K_{z z}$ is the vertical saturated hydraulic conductivity of the underlying porous medium and $L_{c}$ is a coupling length [L]. 


\section{A.3. Evapotranspiration equations}

The actual evapotranspiration is calculated by HydroGeoSphere according to the model of Kristensen and Jensen (1975).

$$
\begin{aligned}
& T_{p=} f_{1}(L A I) f_{2}(\theta) \operatorname{RDF}\left(L_{r}\right)\left\lfloor E_{p}-E_{\text {can }}\right\rfloor \\
& f_{1}(\mathrm{LAI})=\max \left\{0, \min \left[1,\left(C_{2}+C_{1} \cdot \mathrm{LAI}\right)\right]\right\}
\end{aligned}
$$$$
f_{2}= \begin{cases}0 & \text { for } \quad 0 \leq \theta \leq \theta_{t 2} \\ 1-\left[\frac{\theta_{t 1}-\theta}{\theta_{t 1}-\theta_{t 2}}\right]^{C_{3}} & \text { for } \quad \theta_{t 2} \leq \theta \leq \theta_{t 1} \\ 1 & \text { for } \quad \theta_{t 1} \leq \theta\end{cases}
$$$$
E_{s=} \alpha^{*}\left(E_{p}-E_{\text {can }}\right) 1-f_{1}(\mathrm{LAI}) \operatorname{EDF}\left(L_{e}\right)
$$$$
\alpha^{*}= \begin{cases}0 & \text { for } \quad \theta<\theta_{e 2} \\ \frac{\theta-\theta_{e 2}}{\theta_{e 1}-\theta_{e 2}} & \text { for } \quad \theta_{e 2} \leq \theta \leq \theta_{e 1} \\ 1 & \text { for } \quad \theta>\theta_{e 1}\end{cases}
$$

$S_{\text {int }}^{\max }=C_{\text {int }} \mathrm{LAI}$

The actual transpiration $T_{p}\left[\mathrm{~L} \mathrm{~T}^{-1}\right]$ and evaporation $E_{s}\left[\mathrm{~L} \mathrm{~T}^{-1}\right]$ are calculated as a function of the potential evapotranspiration $E_{p}$ $\left[\mathrm{L} \mathrm{T}^{-1}\right]$, and the soil moisture $\theta[-]$ at each node belonging to the specified evaporative and root zones. $\operatorname{RDF}\left(L_{r}\right)$ and $\operatorname{EDF}\left(L_{e}\right)$ are the 'Root Distribution Function' and the 'Evaporation Distribution Function', respectively. These two functions distribute the water extracted along the root depth $L_{r}[\mathrm{~L}]$ and evaporation depth $L_{e}$ [L], respectively, following a quadratic law. The "canopy evaporation' $E_{\text {can }}\left[\mathrm{L} \mathrm{T}^{-1}\right]$ corresponds to the evaporation of water intercepted by the canopy. The interception of precipitation by the canopy is dependent on the 'interception storage capacity' $S_{\text {int }}^{\max }$ [L], which represents the maximum quantity of water that can be intercepted by the canopy. It depends on the 'Leaf Area Index' (LAI) and the 'canopy storage parameter' $c_{\text {int }}[\mathrm{L}] . \theta_{e 1}, \theta_{e 2}, \theta_{t 1}, \theta_{t 2}$ are the evaporation and transpiration limiting water contents, respectively. C1, C2 and C3 correspond to transpiration fitting parameters.

\section{References}

Ali, R., McFarlane, D., Varma, S., Dawes, W., Emelyanova, I., Hodgson, G., Charles, S., 2012. Potential climate change impacts on groundwater resources of southwestern Australia. J. Hydrol. 475, 456-472.

Armandine Les Landes, A., Aquilina, L., De Ridder, J., Longuevergne, L., Pagé, C., Goderniaux, P., 2014. Investigating the respective impacts of groundwater exploitation and climate change on wetland extension over 150 years. J. Hydrol. 509, 367-378.

Blenkinsop, S., Harpham, C., Burton, A., Goderniaux, P., Brouyère, S., Fowler, H.J., 2013. Downscaling transient climate change with a stochastic weather generator for the Geer catchment, Belgium. Climate Research 57 (2), 95-109.

Brouyère, S., Carabin, G., Dassargues, A., 2004a. Climate change impacts on groundwater resources: modelled deficits in a chalky aquifer, Geer basin, Belgium. Hydrogeol. J. 12, 123-134.

Brouyère, S., Dassargues, A., Hallet, V., 2004b. Migration of contaminants through the unsaturated zone overlying the Hesbaye chalky aquifer in Belgium: a field investigation. J. Contam. Hydrol. 72 (1-4), 135-164.

Brunner, P., Simmons, C.T., 2012. HydroGeoSphere: a fully integrated, physically based hydrological model. Ground Water 50 (2), 170-176.

Burton, A., Kilsby, C.G., Fowler, H.J., Cowpertwait, P.S.P., O'Connell, P.E., 2008. RainSim: a spatial-temporal stochastic rainfall modelling system. Environ. Model. Softw. 23 (12), 1356-1369.

Dams, J., Salvadore, E., Van Daele, T., Ntegeka, V., Willems, P., Batelaan, O., 2012. Spatio-temporal impact of climate change on the groundwater system. Hydrol. Earth Syst. Sci. 16 (5), 1517-1531.

Déqué, M., Rowell, D., Lüthi, D., Giorgi, F., Christensen, J., Rockel, B., Jacob, D., Kjellström, E., de Castro, M., van den Hurk, B., 2007. An intercomparison of regional climate simulations for Europe: assessing uncertainties in model projections. Clim. Change 81, 53-70.

Ebel, B.A., Mirus, B.B., Heppner, C.S., VanderKwaak, J.E., Loague, K., 2009. First-order exchange coefficient coupling for simulating surface water-groundwater interactions: parameter sensitivity and consistency with a physics-based approach. Hydrol. Process. 23 (13), 1949-1959.

Goderniaux, P., Brouyère, S., Fowler, H.J., Blenkinsop, S., Therrien, R., Orban, P., Dassargues, A., 2009. Large scale surface-subsurface hydrological model to assess climate change impacts on groundwater reserves. J. Hydrol. 373 (1-2), $122-138$.

Goderniaux, P., Brouyère, S., Blenkinsop, S., Burton, A., Fowler, H.J., Orban, P., Dassargues, A., 2011. Modeling climate change impacts on groundwater resources using transient stochastic climatic scenarios. Water Resour. Res. 47 (12).

Green, T.R., Taniguchi, M., Kooi, H., Gurdak, J.J., Allen, D.M., Hiscock, K.M., Treidel, H., Aureli, A., 2011. Beneath the surface of global change: impacts of climate change on groundwater. J. Hydrol. 405 (3-4), 532-560.

Hallet, V., 1998. Etude de la contamination de la nappe aquifère de Hesbaye par les nitrates: hydrogéologie, hydrochimie et modélisation mathématique des écoulements et du transport en milieu sature (Contamination of the Hesbaye aquifer by nitrates: hydrogeology, hydrochemistry and mathematical modeling), PhD thesis, University of Liège, Liège (Belgium), 361pp.

Henriksen, H.J., Troldborg, L., Nyegaard, P., Sonnenborg, T.O., Refsgaard, J.C., Madsen, B., 2003. Methodology for construction, calibration and validation of a national hydrologic model for Denmark. J. Hydrol. 280, 52-71.

Herrera-Pantoja, M., Hiscock, K.M., 2008. The effects of climate change on potential groundwater recharge in Great Britain. Hydrol. Process. 22 (1), 73-86.

Hill, M.C., Tiedeman, C.R., 2007. Effective groundwater model calibration. With analysis of data sensitivities predictions and uncertainty. John Wiley \& Sons New Jersey, 455pp.

Holman, I., Allen, D., Cuthbert, M., Goderniaux, P., 2012. Towards best practice for assessing the impacts of climate change on groundwater. Hydrogeol. J. 20 (1) $1-4$.

Hornberger, M.G., Raffensperger, J.P., Wilberg, P.L., Eshleman, K.L., 1998. Elements of Physical Hydrology. JUH Press, 312pp.

Jackson, C.R., Meister, R., Prudhomme, C., 2011. Modelling the effects of climate change and its uncertainty on UK Chalk groundwater resources from an ensemble of global climate model projections. J. Hydrol. 399 (1-2), 12-28.

Kilsby, C.G., Jones, P.D., Burton, A., Ford, A.C., Fowler, H.J., Harpham, C., James, P., Smith, A., Wilby, R.L., 2007. A daily weather generator for use in climate change studies. Environ. Model. Softw. 22 (12), 1705-1719.

Konikow, L.F., Person, M., 1985. Assessment of long-term salinity changes in an irrigated stream-aquifer system. Water Resour. Res. 21.

Kristensen, K.J., Jensen, S.E., 1975. A model for estimating actual evapotranspiration from potential evapotranspiration. Nord. Hydrol. 6, 170-188.

Nakicenovic, N. et al., 2000. Emissions scenarios. A Special Report of Working Group III of the Intergovernmental Panel on Climate ChangeRep.. Cambridge University Press, Cambridge, 559pp.

Neukum, C., Azzam, R., 2012. Impact of climate change on groundwater recharge in a small catchment in the Black Forest, Germany. Hydrogeol. J. 20 (3) $547-560$.

Orban, P., Brouyere, S., Batlle-Aguilar, J., Couturier, J., Goderniaux, P., Leroy, M., Maloszewski, P., Dassargues, A., 2010. Regional transport modelling for nitrate trend assessment and forecasting in a chalk aquifer. J. Contam. Hydrol. 118 (12), 79-93.

Poeter, E.P., Hill, M.C., Banta, E.R., Mehl, S., Christensen, S., 2005. UCODE_2005 and Six Other Computer Codes for Universal Sensitivity Analysis, Calibration, and Uncertainty Evaluation, U.S. Geological Survey Techniques and Methods 6-A11, 283pp.

Refsgaard, J.C., 1997. Parameterisation, calibration and validation of distributed hydrological models. J. Hydrol. 198 (1-4), 69-97.

Rojas, R., 2009. Uncertainty analysis in groundwater modelling: an integrated approach to account for conceptual model uncertainty, PhD thesis, Katholiek Universiteit Leuven. Faculty of Science, Leuven, 150pp.

Rojas, R., Batelaan, O., Feyen, L., Dassargues, A., 2009. Assessment of conceptua model uncertainty for the regional aquifer pampa del Tamarugal. Hydrol. Earth Syst. Sci. Discuss. 6 (5), 5881-5935.

Scibek, J., Allen, D.M., Cannon, A.J., Whitfield, P.H., 2007. Groundwater-surface water interaction under scenarios of climate change using a high-resolution transient groundwater model. J. Hydrol. 333 (2-4), 165-181.

Serrat-Capdevila, A., Valdés, J.B., Pérez, J.G., Baird, K., Mata, L.J., Maddock Iii, T., 2007 Modeling climate change impacts - and uncertainty - on the hydrology of a riparian system: the San Pedro Basin (Arizona/Sonora). J. Hydrol. 347 (1-2), 48 66.

Stoll, S., Hendricks Franssen, H.J., Butts, M., Kinzelbach, W., 2011. Analysis of the impact of climate change on groundwater related hydrological fluxes: a multimodel approach including different downscaling methods. Hydrol. Earth Syst. Sci. 15 (1), 21-38.

Sulis, M., Paniconi, C. Marrocu, M. Huard, D. Chaumont, D. 2012. Hydrologic response to multimodel climate output using a physically based model of groundwater/surface water interactions. Water Resour. Res. 48 (12).

Therrien, R., McLaren, R.G., Sudicky, E.A., Panday, S.M., 2010. HydroGeoSphere. A three-dimensional numerical model describing fully-integrated subsurface and surface flow and solute transport, 443pp.

Van Roosmalen, L., Sonnenborg, T.O., Jensen, K.H., 2009. Impact of climate and land use change on the hydrology of a large-scale agricultural catchment. Water Resour. Res. 45 (7).

Vecchia, A.V., Cooley, R.L., 1987. Simultaneous confidence and prediction intervals for nonlinear regression models with application to a groundwater flow model. Water Resour. Res. 23 (7), 1237-1250. 
Wildemeersch, S., Goderniaux, P., Orban, P., Brouyère, S., Dassargues, A., 2014 Assessing the effects of spatial discretization on large-scale flow model performance and prediction uncertainty. J. Hydrol. 510, 10-25.

Woldeamlak, S., Batelaan, O., De Smedt, F., 2007. Effects of climate change on the groundwater system in the Grote-Nete catchment, Belgium. Hydrogeol. J. 15 (5), 891-901.
Wood, A.W., Leung, L.R., Sridhar, V., Lettenmaier, D.P., 2004. Hydrologic implications of dynamical and statistical approaches to downscaling climate model outputs. Clim. Change 62 (1), 189-216.

Zhou, Y., Zwahlen, F., Wang, Y., Li, Y., 2010. Impact of climate change on irrigation requirements in terms of groundwater resources. Hydrogeol. J. 18 (7), 15711582. 